\title{
A Simulation Analysis on the Expected Horizontal Accuracy of a Bridge Stakeout
}

\author{
Nedim TUNO, Jusuf TOPOLJAK, Naida ADEMOVIĆ, Admir MULAHUSIĆ
}

\begin{abstract}
The positioning of an object in space, i.e. "transfer" of data from the design to the field is an extremely significant and important geodetic operation. This activity requires great and well-deserved attention, especially when it comes to sensitive structures such as bridges. The position of a stakeout point in the field depends on a variety of different influences, all determining the actual accuracy of the stakeout. The aim of this Article is to investigate the dependency of horizontal setting out of the bridge axis accuracy (abutments and piers of the bridge) from the distance between the station and the setout point, the datum of the geodetic control network, and the precision of angular and linear measurements. The authors use an innovative visualization technique for the assessment of spatial variation of the horizontal stakeout by error ellipses.
\end{abstract}

Keywords: error ellipse; geodetic network adjustment; stakeout accuracy; staking bridge axis

\section{INTRODUCTION}

Bridge construction requires a joint participation of experts from various fields, including those from the field of geodesy [1]. During construction, survey activities are conducted during different phases, starting with the production of the large-scale engineering plan (map), pier and abutment stakeout, to the monitoring of eventual displacement and deformations of the bridge during its exploitation $[2,3]$. Survey measurements of the structure displacement before and after earthquakes are of the utmost importance for further bridge usage [4].

The stakeout of bridges is one of the most important tasks for surveying engineers. Through it the geometry of the designed structure is transferred on site - both in a horizontal and vertical sense [5]. During such a task it is important to know the required precision of the stakeout, which is defined through the permitted deviations for the measurement and geometrical tolerances connected with the structure's location. On the basis of the coordinate errors of the control geodetic network, and errors in stakeout element measurements, it is possible to predict the accuracy that will be achieved during the stakeout of the structures' individual points. It is important to emphasize that the achieved accuracy of the stakeout should be smaller than the required one [6].

Recent research of stakeout accuracy predictions was mostly directed towards the analysis of optimal procedures for satisfying the accuracy requirements. In [6] the influence of the geodetic network design, the measurements and selection of the appropriate instruments for stakeout accuracy were analyzed. It was shown that in most cases the required accuracy could be obtained by using measurements with only one face of the instrument. Investigation results [7] showed that during the assembly of the concrete and steel elements, a very high measurement precision needed to be obtained, and based upon this, a revision of the current standard - ISO 4463 - (Measurement methods for building - Setting-out and measurement) [8] was proposed and updated. However, during the comprehensive analysis of the standards of civil engineering structures in terms of their geometry, the authors of the article [9] define the criteria for the acceptance of geodetic measurement results. The investigation [10] draws attention to specific ways for defining the stakeout uncertainty index - particularly on the basis of the variance-covariance matrix.

In most of the stakeout research, global and local position accuracy of the points is expressed through standard deviation in the direction of the coordinate axis or total positional error. The problem with this kind of accuracy prediction is that it does not provide an insight into predicted accuracy of stakeout points within any direction - a factor which is usually critical. In this article the horizontal accuracy of the stakeout is analyzed through absolute error ellipses, wherein the stakeout points actually lie. In terms of a concrete example of the geodetic network, established for the bridge construction, the uncertainty of the point stakeout depending on the selection of the datum of the geodetic network, the distance between the designed points of the structure and points of the geodetic network, the accuracy of the geodetic instrument and the centering error were tested and analyzed.

\section{GEODETIC ACTIVITIES DURING THE DESIGN AND EXECUTION OF BRIDGES}

Bridges - in a broader sense - have the primary purpose of continuing roads while also representing structures by which certain barriers are crossed [11]. Each and every bridge structure needs to fulfill four basic requirements: a functional demand, a stable demand (security, stability and durability), an aesthetic demand, and an economic demand [12]. Geodetic activities that are completed for bridge execution are: a survey of the site and production of large-scale plans, establishment of the horizontal and vertical control networks, stakeouts, monitoring, supervision, and control of execution [13]. Each operation where a new bridge structure is being built or an old bridge structure is being rehabilitated, is comprised of numerous tasks where geodesy remains critical; in both the engineering geodesy part of the design and in the cadastral-geodetic part of the project.

A control network of points is established for the purpose of bridge execution. This network can be used for the production of the base map for the purpose of bridge design, for the stakeout, and for bridge monitoring during the execution process. The position of the permanent geodetic points within the network depends on: the size 
and distribution of the structure, configuration of the land surface, and the method of observations for determining control point coordinates. Usually - for the purposes of the bridge - a network in the shape of a square, or rectangle and triangle and two rectangles, or similar, is set up [14]. The longer the bridge the more the control network adopts a snake-like shape [13]. The positioning of the control network points should be such as to ensure the required accuracy of setting-out the bridge structure [5]. In regard to accuracy, the highest demands are placed upon the stakeout of the bridge's substructure (columns, abutment), so the control network needs to be adjusted accordingly. High demands regarding the accuracy of the control network for bridge execution, require a reliable stabilization that will serve such a purpose and be less prone to deformations during the structure's execution [2]. The bridge control networks are established by terrestrial or satellite methods (Global Navigation Satellite System - GNSS) or, as is currently most popular, a combination of these two methods [15].

\section{THE HORIZONTAL SETTING OUT}

Transferring the designed structures on site is defined as staking (setting or laying) and is done in horizontal and vertical planes. This research will only examine horizontal setting. In order to start with the stakeout of the object on site, it is necessary to determine the setting out elements. The vast majorities of today's building designs are constructed digitally and are defined in the twodimensional Cartesian coordinate system $(y, x)$. So, the staking elements are done analytically, and thus for their transfer on the site, the coordinate method $[16,17]$ is used. This means that the layout of the horizontal setting out points is done on the basis of control network and the design coordinates of points that need to be staked out, using selected surveying instruments.

A detailed description of the geodetic datum and coordinate systems is provided in the relevant literature, i.e. $[18,19,20]$.

Staking a building's position of design points is most frequently performed by polar and satellite RTK (Real Time Kinematic) GNSS method, and sometimes by the intersection of the sight lines [21]. The RTK method is characterized by a short time interval needed for the determination of the coordinates for individual points, and is highly economical [2]. Due to the strict limits of geometric tolerances within a bridge substructure, the obtained accuracy of results from RTK measurements $[22,23]$ does not meet the needs of their stakeout. Another disadvantage is that this method requires fulfillment of numerous measurement conditions. It is particularly important that there are no nearby reflective surfaces which would cause multipath signals; a feat difficult to achieve in practice [24]. For these reasons the polar method of staking continues to be the most practiced procedure [6].

The principal of staking via the polar method is based on marking a large number of the structure's points from a single control (known) point $A$. The instrument (electronic tacheometer - total station) is oriented in a known bearing toward the second known point B (Fig. 1). The new point $\mathrm{P}$ is then set up by the bearing $v_{P}$ and length $d$ which are determined from their known Cartesian coordinates $(y, x)[16]$, according to Eq. (1):

$\alpha=v_{P}-v_{B}=\operatorname{atan} \frac{y_{P}-y_{A}}{x_{P}-x_{A}}-\operatorname{atan} \frac{y_{B}-y_{A}}{x_{B}-x_{A}}$

$d=\sqrt{\left(y_{P}-y_{A}\right)^{2}+\left(x_{P}-x_{A}\right)^{2}}$

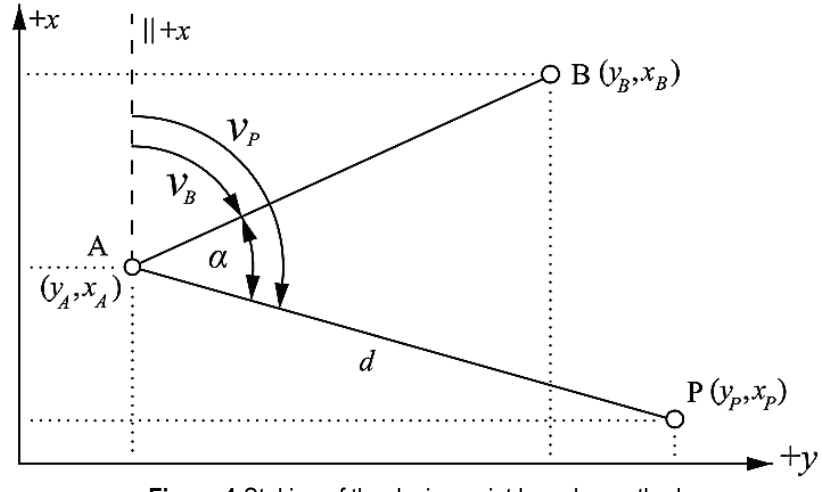

Figure 1 Staking of the design point by polar method

\section{ACCURACY OF POINT STAKEOUT BY POLAR METHOD}

Before starting any work on a stakeout, it is necessary to check the quality of the geodetic network and decide what type of measurements should be used in order to achieve the required accuracy. Assessing the quality of the geodetic operations and drawing the appropriate conclusions relies on the least squares estimation - a powerful statistical technique known as rigorous method or adjustment. Least squares techniques used for carrying out the analysis and adjustment of survey measurements are explained in the relevant literature, i.e. [25, 26, 27].

The required accuracy does not depend on measurements; instead its definition is based on the characteristics of the designed structure that is to be transferred to the site. The required accuracy is usually defined by the required standard deviation $\tau_{P}$ of each staking point. Staking of the design point $\mathrm{P}$ with polar coordinates is realized by measuring the horizontal angle $\alpha$ and horizontal distance $d$, using two points with known coordinates, A and B. The accuracy obtained in this way is defined as a resultant of known coordinate errors and the measurement errors of stakeout elements $(\alpha, d)$. This accuracy is usually expressed as achieved horizontal deviation $\sigma_{P}$. Taking into account all the relevant components of errors, during the planning of the stakeout process it is important to satisfy the criteria in Eq. (2) [6]:

$\left|\sigma_{P}\right| \leq\left|\tau_{P}\right|$

Typically, geometrical tolerances of civil engineering structures are expressed across certain axes; and the obtained value of horizontal deviations are as well expressed in the directions of coordinate axes [7]. In regard to polar staking, transverse $\sigma_{q}$ and longitudinal deviation $\sigma_{l}$ are considered in the local polar coordinate system (Fig. 2). These values do not provide complete information regarding the accuracy of the points' location. The uncertainty of the position is likely not known in any direction other than those of the coordinate axes. It is much better if the uncertainty of the horizontal 
position of a point is expressed in a graphical format by the error ellipse. In practice it is common to calculate the error ellipse with a $5 \%$ significance level $(\alpha=0.05)$. In order to calculate the elements of the error ellipse, it is necessary to have a variance-covariance matrix of orthogonal coordinate points. The variance-covariance matrix of stakeout points - more precisely the coordinates of points - follows from the error propagation law. For its calculation, according to Eq. (3), variance-covariance matrix of initial starting points $\left(\boldsymbol{C}_{\boldsymbol{P}}\right)$, vector measurements $(\boldsymbol{l})$ with its variance-covariance matrix $\left(\boldsymbol{C}_{\boldsymbol{l}}\right)$ and functional relation between calculated coordinates and measurements $[(x=f(l)]$ are required [17]:

$\boldsymbol{C}_{\boldsymbol{x}}=\left(\begin{array}{cc}\sigma_{1} & \sigma_{12} \\ \sigma_{21} & \sigma_{2}\end{array}\right)=\boldsymbol{C}_{\boldsymbol{P}}+\boldsymbol{B} \cdot \boldsymbol{C}_{\boldsymbol{l}} \cdot \boldsymbol{B}^{\mathrm{T}}$

The $\boldsymbol{B}$ matrix is a Jacobian matrix. It is a matrix of the vectors' partial derivatives of coordinate parameters in respect to the measurement vector, defined by Eq. (4):

$\boldsymbol{B}=\frac{\partial x}{\partial l}$

Elements of the error ellipse, the sizes of semi-major and semi-minor axes $(a$ and $b)$ and the orientation of the major axis (angle $\Theta$ ) are calculated according to Eq. (5):

$\tan 2 \Theta=\frac{2 \cdot \sigma_{12}}{\sigma_{1}-\sigma_{2}}$

$a=\sqrt{\frac{1}{2}\left(\sigma_{1}^{2}+\sigma_{2}^{2}+\sqrt{\left(\sigma_{1}^{2}-\sigma_{2}^{2}\right)^{2}+4 \cdot \sigma_{12}^{2}}\right)}$

$b=\sqrt{\frac{1}{2}\left(\sigma_{1}^{2}+\sigma_{2}^{2}-\sqrt{\left(\sigma_{1}^{2}-\sigma_{2}^{2}\right)^{2}+4 \cdot \sigma_{12}^{2}}\right)}$

The calculations according to Eq. 5 produce standard error ellipse [27]. The chance that the point actually lies within the standard error ellipse is 39\% [21]. The method of obtaining the $95 \%$ error ellipse depends on whether the variance-covariance matrix of the population is unknown [17].

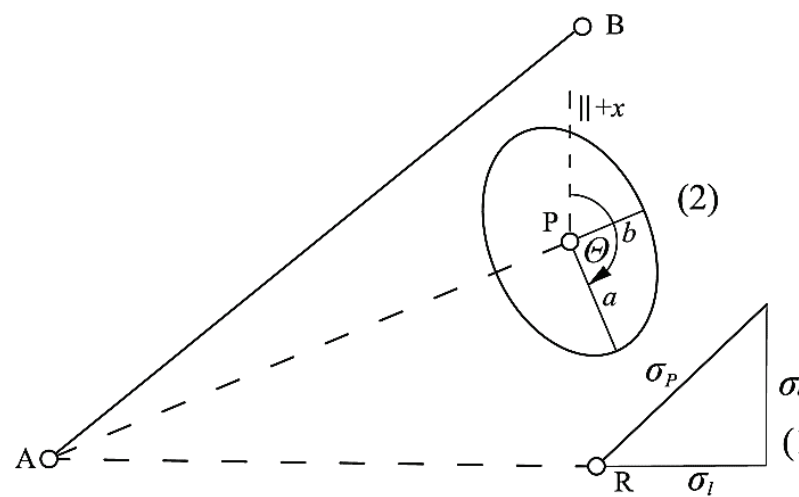

Figure 2 Uncertainty prediction of the stake out by the polar method: (1) transversal, longitudinal and horizontal deviation; (2) error ellipse

To express the predicted uncertainty of twodimensional position of stakeout points, error circles can be used with an appropriate level of confidence; this is referred to as CEP (Circular Error Probable) [28]. The radius of the standard circle, which incorporates $50 \%$ of the points, is calculated by Eq. (6):

$$
C E P=0.59 \cdot(a+b) \pm 3 \% \text {, for } b / 3<a<3 \cdot b
$$

An error circle with $95 \%$ confidence level is determined by Eq. (7):

$$
C E P_{95 \%}=2.08 \cdot C E P
$$

\section{EMPIRICAL CASE STUDY}

The testing and analysis of the data in this study were carried out on the bridge (overpass) "Ciglane", located in the metropolitan area of Sarajevo, Bosnia and Herzegovina (Fig. 3).

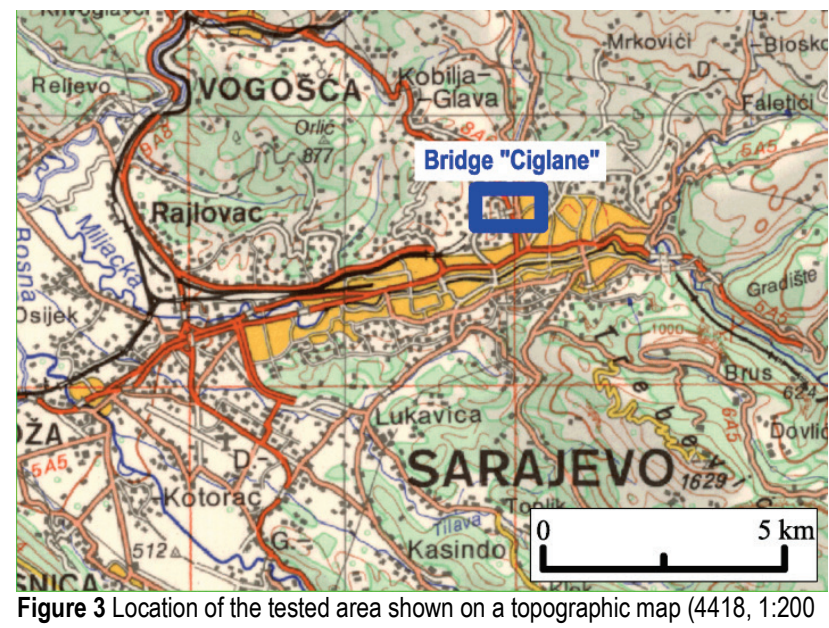

$$
\text { 000, Military geographical institute Belgrade, 1972) }
$$

\subsection{Brief Description of the Tested Structure}

The bridge was designed in 1976 as part of an urban highway (Fig. 4). This highway was foreseen as an extension of the M5 highway, the European road E761 through Sarajevo. It was to begin at the eastern entrance of the city, leading the Sarajevo's northern area to the west, whereby it would be connected to the A1 highway at the end. The bridge was supposed to have two separate carriage ways, one for each direction. The bridge was partially built before the aggression on Bosnia and Herzegovina in 1992 after which all works were suspended. The completed southern structure with its two lanes is currently used as part of the local improvised road (Fig. 5).

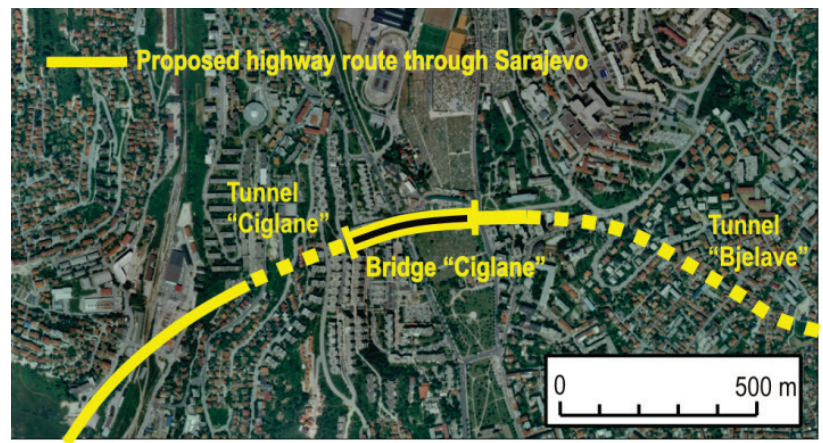

Figure 4 Bridge "Ciglane" as a part of the designed city highway, according to [29], shown on a digital orthophoto $(6 \mathrm{H} 15-5,6 \mathrm{H} 15-6,1: 5000$, Federal ministry of physical planning, 2008) 


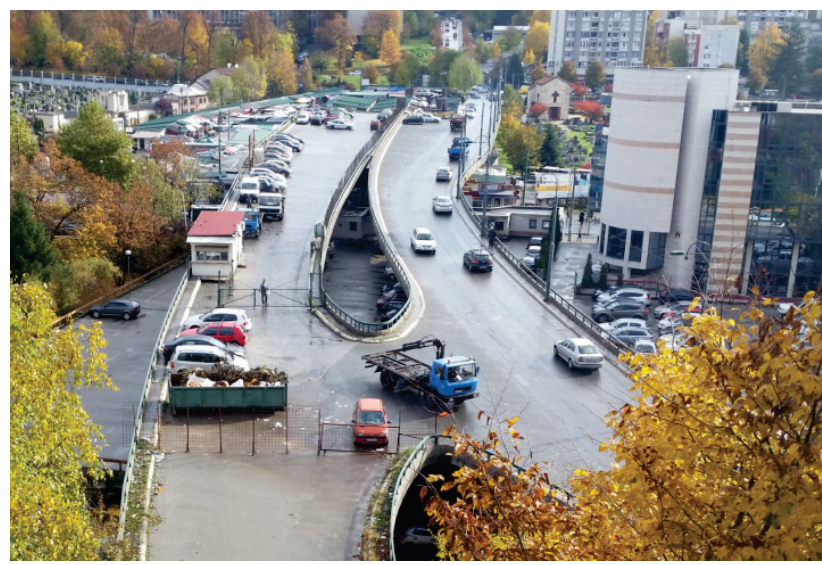

Figure 5 Part of the bridge "Ciglane" which is in use (photo taken by N. Tuno, 2016)

In case of a possible continuation of the construction of the city highway, and thus construction of this bridge, it would be necessary to conduct accurate surveying and stakeouts of the existing and designed parts of the bridge.

\subsection{Horizontal Geodetic Network}

With the aim of testing the optimal stakeout parameters, a pilot micro-triangulation network was established on the site. The establishment of the control network was carried out in three phases: design, execution and analysis.

By using the control network project it was determined where the control points would be placed (configuration) and in which way it would be measured. It was initially anticipated that the network covered an area of 40 ha, and was to be defined by 5 points. Three points are located on the east side of the bridge and two on the west side. Points are located at an average distance of 260 $\mathrm{m}$ (minimum $55 \mathrm{~m}$, maximum $390 \mathrm{~m}$ ). Due to the terrain configuration around the bridge, construction and high vegetation, optimal geometric configuration of the geodetic network was achieved.

By execution of the control network the project became a reality. Work on the network measurements began after the stabilization of points was completed. Measurements in the network were realized by total station Leica Geosystems TC605L. The instrument precision according to DIN18723 [30] was $\sigma_{u}=5 "$ for angle measurement and $\sigma_{d}=3 \mathrm{~mm}+3 \mathrm{ppm}$ for linear measurement [31]. Before measurements started, testing of the instrument was done according to the current ISO standards 17123-3 and 17123-4. Test results confirmed the declared precision. Measurements in the network involved the measurements of the horizontal directions and distances between all points (a total of 20 directions and 20 distances).

Analysis of the geodetic network included the correction and reduction of field measurements, detection and removal of gross and systematic errors, adjustment of a geodetic network by the least squares method (parametric model), statistical testing of estimated measurement residuals, and analysis of the accuracy of the obtained results.

In order to determine the network in space, it is necessary to know the minimum number of parameters required for its positioning according to pre-defined coordinate systems. Since the intent of this study was to examine the accuracy of the stakeout data - dependent on the adopted datum - three adjustments with different definitions of datum parameters of geodetic network were conducted.

The first adjustment was performed using a conventional method, i.e. connecting the network to points with known coordinates in the BosnianHerzegovinian State Coordinate System (points C1 and $\mathrm{C} 2$ ). These two known points defined conventional datum parameters, and their coordinates were fixed during the process of adjustment. In the second case, definition of the network datum was done in a minimally constrained solution. In the adjustment procedure the coordinates of the point $\mathrm{C} 1$ and the $y$ coordinate of the point $\mathrm{C} 2$ were fixed, giving the necessary (minimal) number of network parameters that were taken as error-free. Finally, the free network adjustment was carried out, i.e. defining the optimum datum, without the introduction of points' errorfree coordinates. The algorithms of the aforementioned adjustment of the geodetic networks were provided in [25, $26,27,32]$. The basic indicators of the accuracy analysis of the three adjustment methods are illustrated in Tab. 1.

Table 1 Indicators of the geodetic network quality

\begin{tabular}{|c|c|c|c|c|c|}
\hline Adjustment type & $\begin{array}{c}\text { Reference } \\
\text { standard } \\
\text { deviation } s_{0}\end{array}$ & $\begin{array}{c}\text { Average value of } \\
\text { standard deviation } \\
\text { per } y \text { axis } \bar{s}_{y}(\mathrm{~m})\end{array}$ & $\begin{array}{l}\text { Average value of } \\
\text { standard deviation } \\
\text { per } x \text { axis } \bar{s}_{x}(\mathrm{~m})\end{array}$ & $\begin{array}{c}\text { Maximum value of } \\
\text { standard deviation } \\
\text { per } y \text { axis } \max s_{y}(\mathrm{~m})\end{array}$ & $\begin{array}{c}\text { Maximum value of } \\
\text { standard deviation } \\
\text { per } x \text { axis } \max s_{x}(\mathrm{~m})\end{array}$ \\
\hline Conventional & 4.2 & 0.004 & \begin{tabular}{|c|}
0.008 \\
\end{tabular} & 0.008 & 0.017 \\
\hline Minimally constrained solution & 1.7 & 0.005 & 0.002 & 0.010 & 0.003 \\
\hline Free & 1.7 & 0.002 & 0.001 & 0.002 & 0.002 \\
\hline
\end{tabular}

\subsection{The Accuracy Analysis of a Bridge Stakeout}

According to $[6,7,14]$, there are numerous influences that dictate the accuracy of a stakeout by polar method: operator's errors, weather conditions, the instrumental errors, centering error at the station point, centering error at the observed known point, centering error at the setout point, marking errors, distance between the station point and the setout point, precision of the theodolite, precision of electronic distance meters (EDM), and positional errors of geodetic control points.
It is not possible in the scope of this study to display the analysis of all listed influences that affect the accuracy of staking. However, the effects of distance dependent errors, the accuracy of the coordinates of the geodetic network, the precision of angular and linear measurements and centering errors were addressed. In that respect, 10 points on the bridge structure were considered: piers $\left(S_{i} ; i=1, \ldots, 8\right)$ and abutments $\left(U_{1}\right.$ and $U_{2}$ ), for which accuracy of the stakeout was analyzed using error ellipses and circular errors. 


\subsubsection{Distance between the Station Point and the Setout Point}

Transfer of the calculated stakeout elements (Eq. (1)), with the aim of marking the characteristic points of the designed structure, is usually performed by using electronic tacheometers. The distances are measured with this instrument by electronic means; this is characterized by a much higher speed and range compared to the classical mechanical and optical methods of measurement [33]. Thanks to the high precision of distance measurements (relative deviation amount from $10^{-4}$ to $10^{-7}$ ), radio connections between the surveyors and assistants; electronic guide lights; the implementation of a fully automated universal tacheometer etc., it is now widely considered that the value of a distance between the station point and the project point does not play an important role in staking.

In order to determine whether, and to what extent, the distance $d$ affects the quality of stakeout, the study examines how an increased distance is reflected on the horizontal accuracy of setout points. Here, the coordinates of the control network, obtained on the basis of

adjustment by defining the optimal datum, were adopted. It was assumed that the staking would be done with the instrument having the same accuracy as the one used in the network measurement $\left[\sigma_{u}=5 ", \sigma_{d}=(3 \mathrm{~mm}+3 \mathrm{ppm})\right]$. Point C3 was used as a station point in the first test and parameters of error ellipse were then calculated, as well as circular errors for all 10 points of the bridge. After that, indicators of accuracy were calculated for the points on the bridge structure, assuming that the stakeout was performed from point C5. Finally, the third test implied that 5 points on the bridge closer to point $\mathrm{C} 5$ (U1, S1, S2, $\mathrm{S} 3$ and S4) were to be staked out from this station, while the points S5, S6, S7, S8 and U2 were to be staked out from $\mathrm{C} 3$. The main indicators of the performed tests are shown in Fig. 6 and in Tab. 2.

Table 2 Quality indicators of stake out depending on the mutual distance between the station point and point that is being staked

\begin{tabular}{|l|c|c|c|c|c|c|}
\hline \multicolumn{1}{|c|}{ Station } & \multicolumn{2}{|c|}{$\begin{array}{c}\text { C3, distance range of } \\
\text { staking 50-315 m }\end{array}$} & \multicolumn{2}{c|}{$\begin{array}{c}\text { C3 and C5, distance range } \\
\text { of staking 50 - 165 m }\end{array}$} \\
\hline Parameter 95 \% & $a$ & $b$ & $C E P$ & $a$ & $b$ & $C E P$ \\
\hline Average $(\mathrm{m})$ & 0.013 & 0.007 & 0.010 & 0.009 & 0.007 & 0.008 \\
\hline Maximum (m) & 0.020 & 0.008 & 0.014 & 0.011 & 0.008 & 0.010 \\
\hline Minimum (m) & 0.008 & 0.005 & 0.007 & 0.008 & 0.005 & 0.007 \\
\hline
\end{tabular}

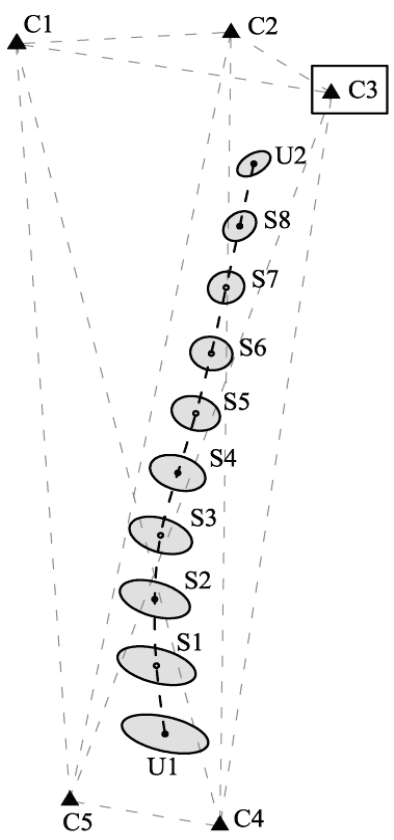

(1)

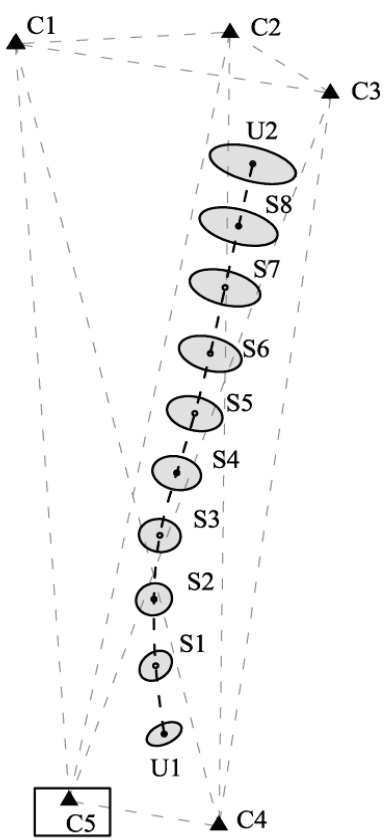

(2)

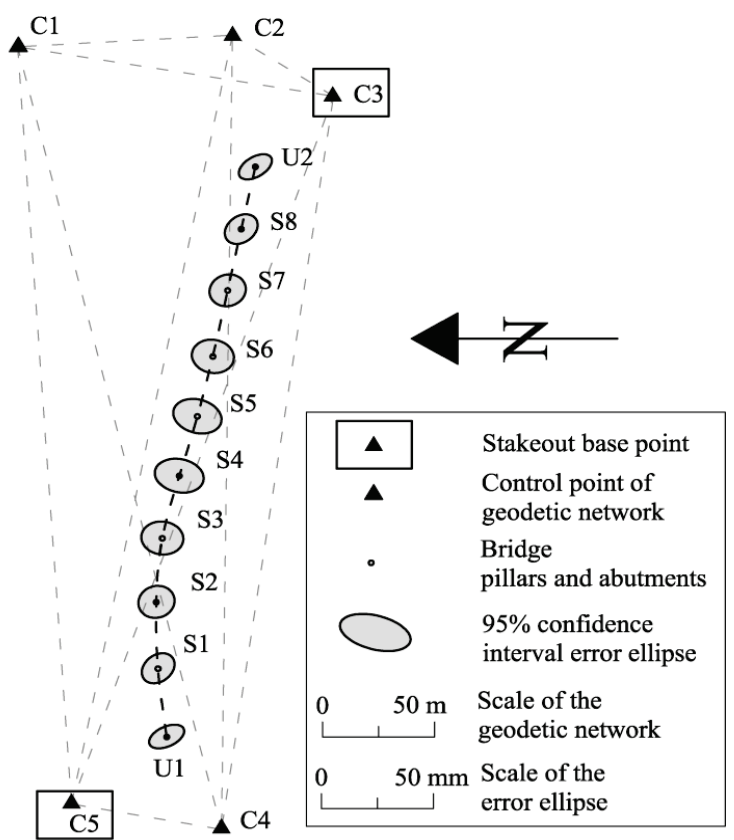

(3)

Figure 6 The influence of the distance of bridge points to the station point on the accuracy of staking: (1) station C3; (2) station C5; (3) stations C3 and C5

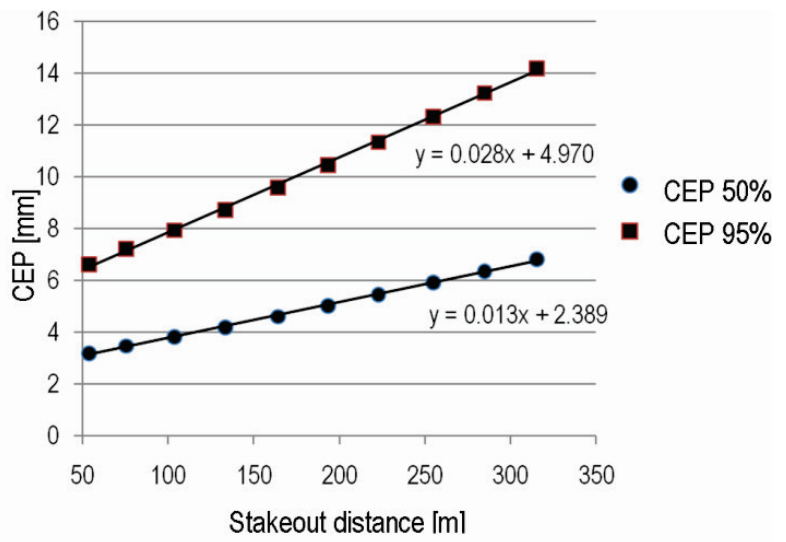

Figure 7 The relationship of distance between the bridge stakeout points and the instrument and the accuracy of staking
By analyzing the accuracy indicators, obtained from these tests, it can be seen that noticeably better results were achieved when the stakeout was performed from two stations, i.e. when the distances are shorter. The relation of the minimum and maximum error ellipse areas in such staking is $1: 2$, as opposed to staking from the only one endpoint, when the ratio is 1:4. Fig. 6 clearly shows that in the case of staking with two stations, error ellipses are more equal than error ellipses obtained by staking from one station. This indicates a significantly greater degree of homogeneity within the obtained results. Increasing the distance has a negative impact on the accuracy of the polar stakeout. Regression lines have a very good relationship between the distance from the 
instrument to set out points and circular errors predicted with $50 \%$ and $95 \%$ level of confidence (see Fig. 7).

\subsubsection{Geodetic Network Datum}

In section 5.2 it was shown that the selection of the datum of the geodetic network directly affects the accuracy of its points' coordinates. With the aim of investigating the impact of datum parameters on the quality of setting-out the bridge, the error ellipse of stakeout points was analyzed herein for all three adopted data. It is assumed that staking was performed from points $\mathrm{C} 3$ and $\mathrm{C} 5$, using an electronic total station with the precision of $\sigma_{u}=5 "$ and $\sigma_{d}=(3 \mathrm{~mm}+3 \mathrm{ppm})$.

If the staking of a bridge is considered by using the geodetic network with conventional definition of the datum and the datum definition with minimally constrained solution, correlation of predicted error ellipses and selected points that define the coordinate system is evident. Points on the bridge that are closer to the chosen origin of the coordinate system have smaller horizontal deviations, and the deviations of points that are further from the origin are higher (ratio of minimum and maximum areas of error ellipses is approximately 1:4) (Tab. 3, Fig. 8). Therefore, with this kind of datum choice, the relative relationship between the points of the bridge cannot be maintained. In other words, homogeneity and isotropy of their accuracy cannot be achieved. The achieved accuracy of staking in the system defined by minimally constrained solution (average value of $\mathrm{CEP}_{95 \%}$ is $15 \mathrm{~mm}$ ) is better around $40 \%$ in respect to the accuracy obtained from the network defined by conventional datum. This refers to the errors related to the inaccuracy of the coordinates of the connecting points in the national coordinate system. The obtained maximum values of the achieved horizontal deviation in both cases exceed the geometrical tolerances for the positioning of base supports and determining the deflection of the bridge piers.

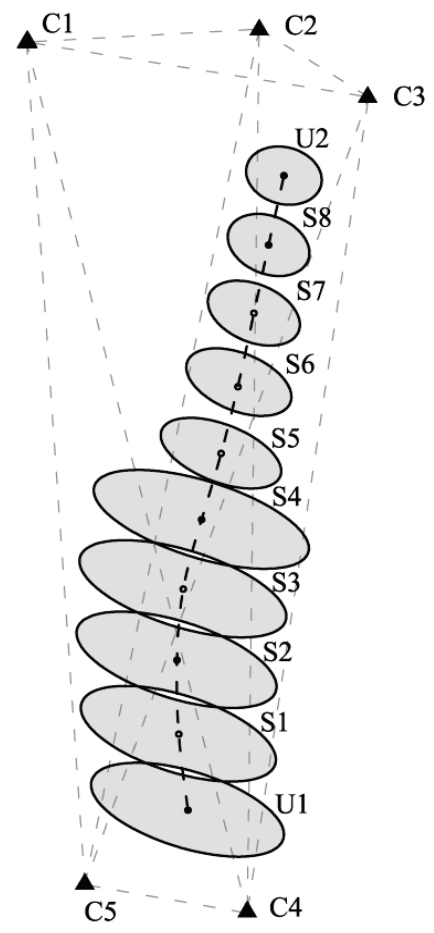

(1)

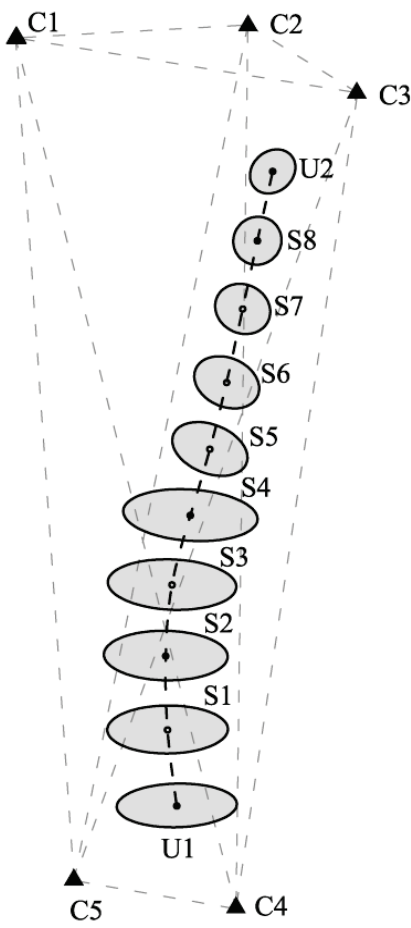

(2)

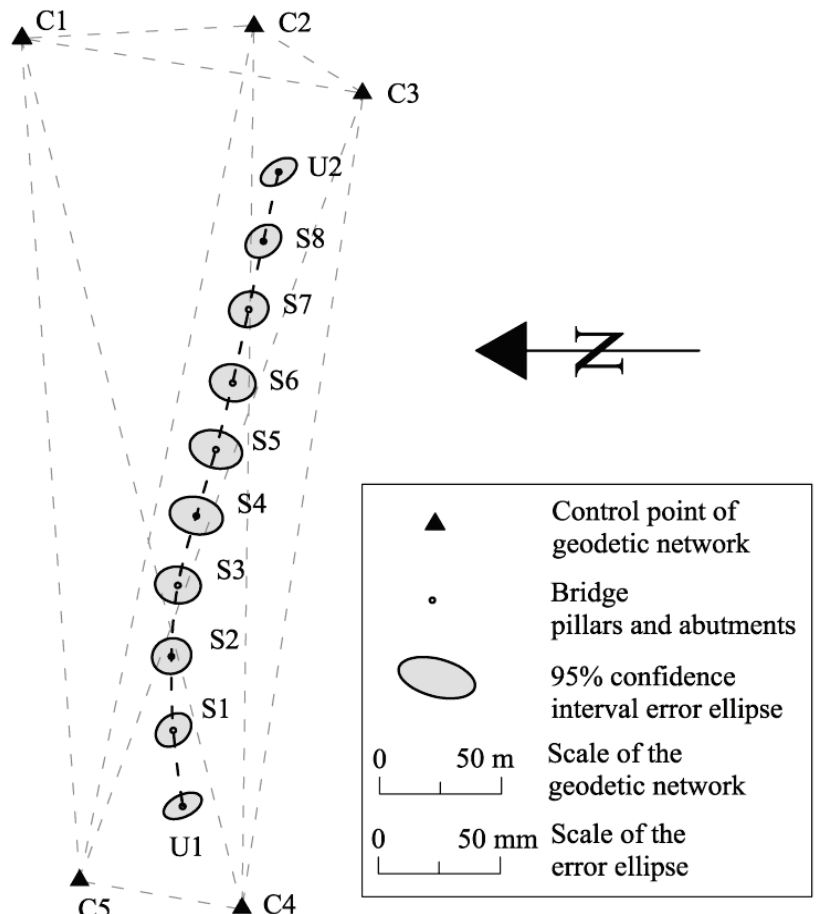

(3)

Figure 8 The influence of the selected geodetic network datum on the accuracy of staking: (1) conventional; (2) minimally constrained solution C5; (3) optimal

Table 3 Indicators of the stakeout quality depending on the datum of the geodetic network

\begin{tabular}{|l|c|c|c|c|c|c|}
\hline \multicolumn{1}{|c|}{ Adjustment type } & \multicolumn{2}{|c|}{ Conventional } & \multicolumn{2}{|c|}{$\begin{array}{c}\text { Minimally } \\
\text { constrained } \\
\text { solution }\end{array}$} & \multicolumn{2}{|c|}{ Free } \\
\hline $\begin{array}{l}\text { Semi-axis of the } \\
\text { ellipse error 95 \% }\end{array}$ & $a$ & $b$ & $a$ & $b$ & $a$ & $b$ \\
\hline Average (m) & 0.033 & 0.014 & 0.020 & 0.010 & 0.009 & 0.007 \\
\hline Maximum (m) & 0.047 & 0.017 & 0.028 & 0.011 & 0.011 & 0.008 \\
\hline Minimum (m) & 0.016 & 0.012 & 0.010 & 0.009 & 0.008 & 0.005 \\
\hline
\end{tabular}

The obtained parameters of staking accuracy resulted from the coordinates of geodetic network defined by the optimal datum; show a more balanced positional strength of all bridge points than in the two previous cases.

In the case of a free geodetic network, a significantly better homogeneity of obtained accuracy was achieved (ratio of minimum and maximum area of error ellipse is approximately 1:2), as well as isotropy (the ratio of average minor and major semi-axis of the ellipse is 1:1.3). Therefore, a more realistic assessment of the accuracy of the bridge's setout points was achieved, while satisfying all requirements.

\subsubsection{The Precision of Electronic Tacheometers}

The selection and usage of appropriate instruments, which provide the favorable results when staking - are often a dilemma in practice. This is due to the large number of different electronic tacheometers models that are used nowadays, all providing a different level of accuracy, efficiency and opportunities. In order to assess 
the influence of measurement uncertainty of angular and linear measurements on the accuracy of staking out, the appropriate parameters which reflect the accuracy of point layout are calculated here. It was assumed that the staking was performed from points C3 and C5, whose coordinates were determined by free adjustment of the network.
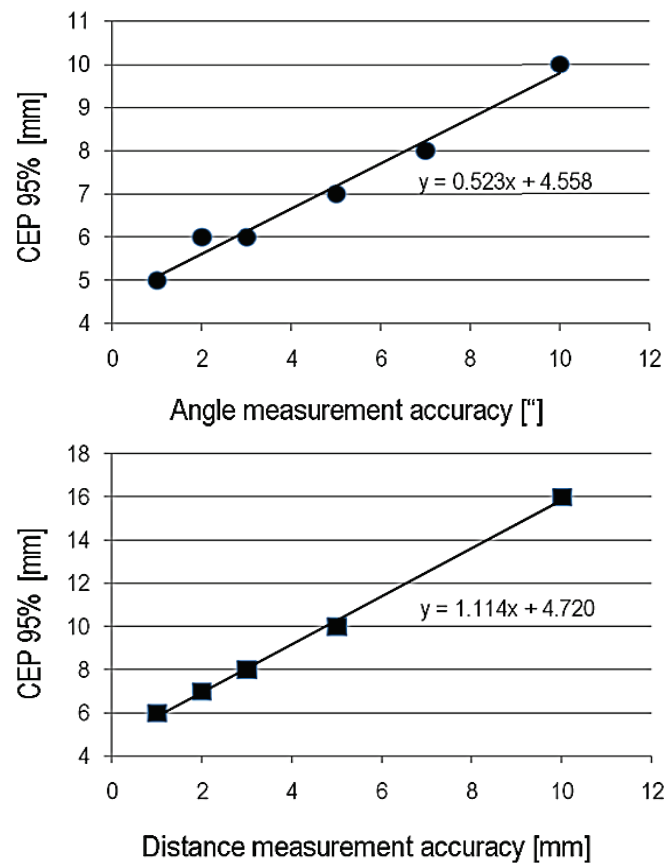

Figure 9 The trend of average values of the accuracy of staking depending on the precision of the total station

The accuracy of staking was considered; if it was done by instruments whose standard deviation of angular measurement was 1", 2", 3", 5", 7" and 10" (with uncertainty of distance measurement of $2 \mathrm{~mm}$ ), and the standard deviation of linear measurements $1 \mathrm{~mm}, 2 \mathrm{~mm}, 3$ $\mathrm{mm}, 5 \mathrm{~mm}$ and $10 \mathrm{~mm}$ (with angular measurement uncertainty 5"). As expected, it was shown that measurements with higher standard deviations led to reduced accuracy of setout points. In Fig. 9 it is visible that the increase of the average staking accuracy $(C E P)$ may be modeled very well with regression lines. The obtained results state that angle measurements with precise tacheometers $\left(\sigma_{u}=1 "\right.$ or better $)$ does not contribute significantly to quality improvement of staking in respect to the total station of standard precision $\left(\sigma_{u}=3 "\right.$ - 5") which is now mostly used in practice. A similar trend is evident with linear measurements, where it is visible that acceptable results were obtained using standard tacheometers $\left(\sigma_{d}=2-3 \mathrm{~mm}\right)$. It should be emphasized that such accuracy of distance measuring can only be achieved in the standard and continuous measurement mode of an EDM instrument. Due to the fact that these electronic distance measurement modes require a longer measurement time, the "tracking" mode of measurements is usually used in practice for staking. Here, the distance is measured very fast but with considerably less accuracy (typically $\sigma_{d}=10 \mathrm{~mm}$ ). Fig. 9 shows that such distance measurement accuracy is not acceptable for more precise staking.

\subsubsection{The Effect of Target Miscentering}

Whenever an instrument or a target is set over a point, there will be some error due to faulty centering. It can be attributed to environmental conditions, plummet errors, quality of optics, personal abilities, and so on [27]. The centering accuracy for a well-adjusted optical plummet, a well-adjusted laser plummet or plumbing rod is about $0.5 \mathrm{~mm} / \mathrm{m}$ (height of instrument or target in meters)[34]. As the tacheometer and target on the observed control point are centered with the aid of an optical or a laser plummet, their centering errors have no significant influence on the accuracy of staking and these errors are not taken into consideration in this paper. On the other hand, the impact of target centering error at the layout point cannot be ignored. Land surveyors conventionally use reflectors mounted to range poles for staking of the design points. The pole is usually hand-held over a target and must be held plumb by a surveyor, with the aid of a bubble level [35]. The position uncertainty of the reflector is closely related to the bubble (level vial) sensitivity (an angular change in the position of the axis of the bubble per $2 \mathrm{~mm}$ of bubble movement). The sensitivity of the most range pole bubbles tends to be in the range of 30 to 60 arc-minutes [36]. For example, if the vial has $60^{\prime}$ sensitivity and the pole is $2 \mathrm{~m}$ tall, the horizontal miscentering would be $35 \mathrm{~mm}$ [37]. Even a careful manual plumbing of the pole can result in the top of the pole being as much as five centimeters out of vertical from the bottom, caused by the human inability to hold a range pole perfectly in the direction of the plumb line [35]. Thus, an inevitable centering error affects the position of each layout point [6].
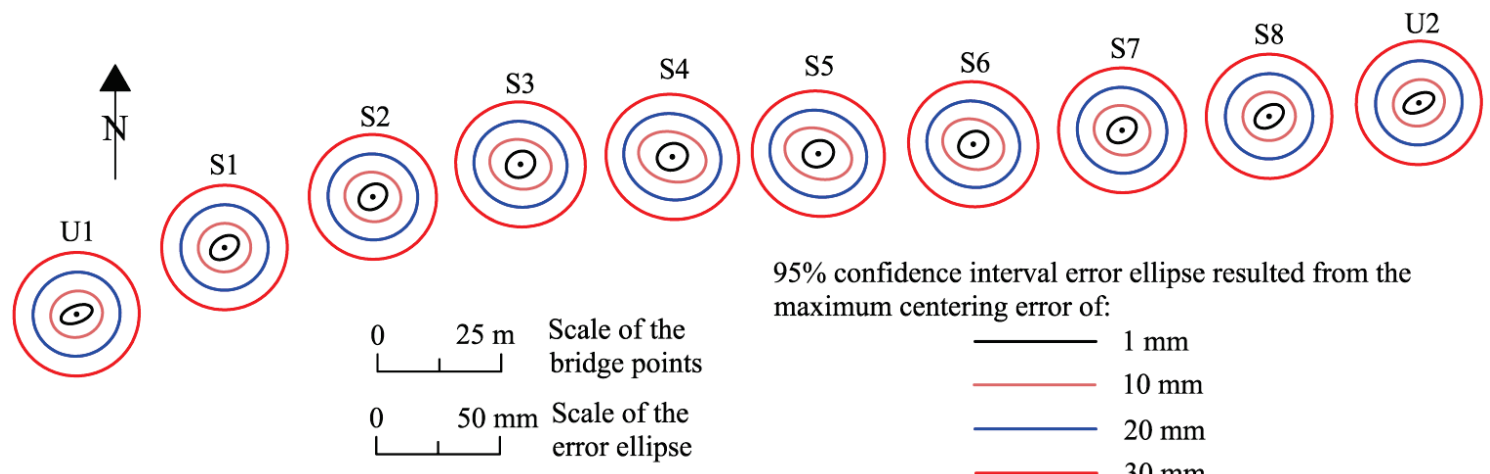

$95 \%$ confidence interval error ellipse resulted from the maximum centering error of:

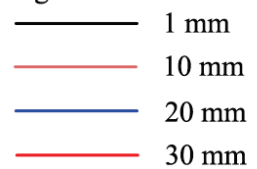

Figure 10 The influence of the distance of bridge points to the station point on the accuracy of staking: (1) station C3; (2) station C5; (3) stations C3 and C5 
In this paper the authors provide the analysis of the effect of target centering error on the achieved bridge point positioning accuracy It is assumed that staking was performed from points $\mathrm{C} 3$ and $\mathrm{C} 5$, with an electronic total station with the precision $\sigma_{u}=5^{\prime \prime}$ and $\sigma_{d}=(2 \mathrm{~mm}+2$ $\mathrm{ppm})$. The errors in angles and distances due to target miscentering were determined according to [6] and [34]. The empirical relation between the maximum expected values of centering errors at the layout points and the resulting error ellipses is illustrated in Fig. 10. Results in Fig. 10 show clearly that target miscentering has strong influence on the achieved point positioning accuracy. The average area of error ellipses, obtained under the assumption that the maximum centering error is $1 \mathrm{~mm}$, is 20 times smaller than those resulting from $30 \mathrm{~mm}$ maximum miscentering. Regression line shows a very good relationship between the maximum centering errors and circular errors predicted with $95 \%$ level of confidence (Fig. 11).

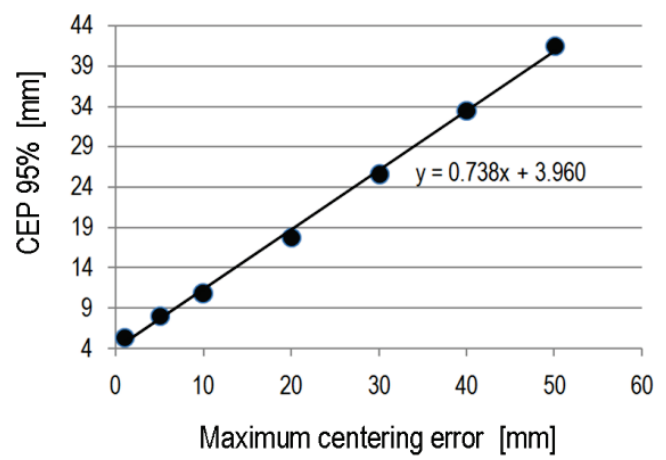

Figure 11 The trend of average values of the accuracy of staking depending on the target centering error

\section{CONCLUSION}

The research results show that the process of bridge stakeouts - as the most sensitive and the most vulnerable structure used for traffic purposes - require a very high accuracy of surveying operations, and, as a consequence, it dictates the accuracy of geodetic control network and instruments that will be used for measurements. The correct choice of stakeout procedure contributes to the avoidance of adverse impacts on the building's execution.

In the stakeout planning process, an optimal solution should be identified in terms of required quality criteria accuracy. Once the configuration of the geodetic network is determined and the measurement method and instrumentation is selected, by utilizing the method of simulation accuracy analysis, it is possible to determine the precision and reliability of points that are to be set out. If the foreseen solution does not meet the required accuracy, a new solution is searched for, until required accuracy is obtained by the simulation.

This study clearly shows that more complete information about the uncertainty of the position of setout points is obtained when using error ellipse, as opposed to the usual methods of accuracy assessment in the directions of the coordinate axes. Other than describing the uncertainty of the staked position of a point, a great advantage of the error ellipses lies in the fact that a visual comparison of achieved accuracy in any two points can be done. This possibility is of great importance in the simulation of different variants of a structure's stakeout. If one looks at their shape, size and orientation, different variants of staking can easily be compared and thus the best one can be selected.

Qualitative examination of the influences that dictate the accuracy of a stakeout by polar method has shown that the choice of the geodetic network datum and target centering accuracy have the greatest influence on the uncertainty of the bridge's point set out. It was noted that the state geodetic network, as well as the network that is adjusted with minimally constrained solution, cannot ensure the stringent requirements of accuracy for bridge substructure stakeouts (piers, abutments and bearings on them). Due to the required accuracy, the geodetic network should be adjusted by defining the optimum datum. To reduce the influence of the target miscentering, it is necessary to use a more sensitive bubble levels, a brace pole or a tripod or bipod to help steady the reflector pole and apply the shortest possible pole height. Since a significant dependence of stakeout accuracy and distance of the bridge points from the geodetic network was shown, it is necessary to ensure that the geodetic control points are sufficiently close to the bridge, in order to perform the setting-out with the shortest possible distances. The use of standard electronic tacheometers can produce satisfactory accuracies of bridge stakeout, but only in a standard and a continuous mode of measurement with the electronic distance meters.

\section{Acknowledgements}

The authors would like to express their deepest gratitude to Nedim Pešto, MA geode., for provided measurement data of the geodetic network for the "Ciglane" bridge.

\section{REFERENCES}

[1] Kapetanović, N., Topoljak, J., Mulahusić, A. \& Selmani, R. (2015). Prilog ispitivanju mogućnosti korištenja instrumenata različitih tehničkih izvedbi pri uspostavljanju nivelmanskih mreža posebnih namjena $u$ inženjerskoj geodeziji. Geodetski glasnik, 46, 7-18.

[2] Kapović, Z. (2010). Geodezija u niskogradnji. Sveučilište u Zagrebu, Geodetskifakultet, Zagreb, Croatia.

[3] Kamnik, R., Kovačić, B., Pribičević, B. \& Đapo, A. (2015). Recentni strukturni sklop i probno ispitivanje jednostavno poduprtog mosta Pernica. Geodetski list, 69(3), 171-188.

[4] Güney, D., Acar, M., Özlüdemir, M. T. \& Çelik, R. N. (2010). Investigation of post-earthquake displacement in viaducts using Geodetic and Finite Element Methods. Natural Hazards and Earth System Sciences, 10(12), 2579258. https://doi.org/10.5194/nhess-10-2579-2010

[5] Paar, R. (2006). Uspostava geodetske osnove za posebne namjene. Msc Thesis, Sveučilište u Zagrebu, Geodetski fakultet, Zagreb, Croatia.

[6] Baykal, O., Tari, E., Coşkun, M. \& Erden, T. (2005). Accuracy of Point Layout with Polar Coordinates. Journal of Surveying Engineering, 131(3), 87-93. https://doi.org/10.1061/(ASCE)0733-9453(2005)131:3(87).

[7] Kala, V. (2009). Some problems of an as-built survey and setting out accuracy. Geodezija i Kartografija, 35(3), 7376. https://doi.org/10.3846/1392-1541.2009.35.73-76.

[8] International Organization for Standardization. ISO 44631:1989: Measurement methods for building -- Setting-out 
and measurement -- Part 1: Planning and organization, measuring procedures, acceptance criteria. 1989. https://www.iso.org/standard/10356.html (25.2.2017)

[9] Pawłowski, W. \& Abbas, S. (2009). Methodology of geodetic surveying for construction in accordance with international standardization. Reports on Geodesy, 87(2), 317-323.

[10] Dąbrowski, J. (2014). Optimization of setting out controls in aspect of stakeout accuracy of engineering objects. Geomatics and Environmental Engineering, 8(3), 27-40. https://doi.org/10.7494/geom.2014.8.3.27.

[11] Pržulj, M. (2014). Mostovi. Udruženje izgradnja, Belgrade, Serbia.

[12] Radić, J. (2002). Mostovi. Domi svijet, Zagreb, Croatia.

[13] Grgić, I., Rezo, M. \& Šabić Grgić, N. (2013). Specifičnosti geodetske osnove i mjernih metoda u graditeljstvu / Neiskorišteni potencijali geodezije, Napuštena i nova područja djelovanja. Zbornik radova VI. Simpozija ovlaštenih inženjera geodezije, Hrvatska komora ovlaštenih inženjera geodezije, Zagreb, Croatia, 105-112.

[14] Pašalić, S. (1995). Inženjerska geodezija. Univerzitet u Sarajevu, Sarajevo, Bosnia and Herzegovina.

[15] Novaković, G. (2006). Geodetske mreže posebnih namjena, unpublished manuscript. Sveučilište u Zagrebu, Geodetski fakultet, Zagreb, Croatia.

[16] Pribičević, B. \& Medak, D. (2003). Geodezija u građevinarstvu. Sveučilište u Rijeci, V.B.Z. d.o.o., Zagreb, Croatia.

[17] Frankić, K. (2012). Inženjerska geodezija, unpublished manuscript. Univerzitet u Sarajevu, Građevinski fakultet, Sarajevo, Bosnia and Herzegovina.

[18] Illife, J. (2000). Datums and Map projections for remote sensing, GIS, and surveying. Whittles Publishing, Caithness, United Kingdom.

[19] Lu, Z., Qu, Y. \& Qiao, S. (2014). Geodesy: Introduction to Geodetic Datum and Geodetic Systems, Springer Berlin Heidelberg, Germany. https://doi.org/10.1007/978-3-642-41245-5

[20] Burkholder, E. (2008). The 3-D Global Spatial Data Model: Foundation of the Spatial Data Infrastructure. CRC Press, Taylor \& Francis Group, Boca Raton, Florida, USA. https://doi.org/10.1201/9781420063035

[21] Schofield, W. \& Breach, M. (2007). Engineering Surveying, $6^{\text {th }}$ edn. Elsevier Ltd., Amsterdam, Netherlands.

[22] El-Mowafy, A. (2004). Surveying with GPS for Construction Works Using the National RTK Reference Network and Precise Geoid Models. The $1^{\text {st }}$ FIG International Symposium on Engineering Surveys for Construction Works and Structural Engineering, Nottingham, United Kingdom.

[23] Khalil, R. (2015). Alternative Solutions for RTK-GPS Applications in Building and Road Constructions. Open Journal of Civil Engineering, 5, 312-321. https://doi.org/10.4236/ojce.2015.53031.

[24] Ata, E. (2014). Signal multipath in high precision GPS surveys. Tehnički vjesnik-Technical Gazette, 21(4), 707713.

[25] Wolf, P. \& Ghilani, C. (1997). Adjustment computations: statistics and least squares in surveying and GIS. Wiley \& Sons, New York, USA.

[26] Harvey, B. R. (2006). Practical Least Squares for Surveyors, 3rd edn. School of Surveying and Spatial Information Systems, University of New South Wales, Kesington, Australia.

[27] Ghilani, C. (2010). Adjustment Computations: Spatial Data Analysis, 5th Edition. John Wiley and Sons Ltd, United Kingdom.

[28] Axelrad, P. (2001). Notes on positioning errors. Course Notes of ASEN5190 GPS Technology. University of
Colorado. http://www.colorado.edu/ASEN/asen5190/ error_notes.pdf (5.10.2016).

[29] Bublin, M. (2006). Sarajevo u istoriji. Buybook, Sarajevo, Bosnia and Herzegovina.

[30] Deutsches Institut für Normung Normenausschuß Feinmechanik und Optik. (1990). Feldverfahren zur Genauigkeits untersuchung geodätischer Instrumente: DIN 18723-3:1990-07 und DIN 18723-6:1990-07. Beuth Verlag, Berlin, Germany.

[31] Tuno, N., Mulahusić, A., Marjetič, A. \& Kogoj, D. (2010). Pregled razvoja elektronskih tahimetrov Leica geosystems. Geodetski vestnik, 54(4), 643-660. https://doi.org/10.15292/geodetski-vestnik.2010.04.643-660

[32] Mihailović, K. \& Aleksić, I. (2008). Koncepti mreža u geodetskom premeru. Geokarata, Belgrade, Serbia.

[33] Benčić, D. \& Solarić, N. (2008). Mjerni instrumenti $i$ sustavi u geodeziji i geoinformatici. Školska knjiga, Zagreb, Croatia.

[34] Ogundare, J. O. (2015). Precision Surveying: Principles and Geomatics Practice. John Wiley \& Sons, Hoboken, New Jersey, USA. https://doi.org/10.1002/9781119147770

[35] Nichols, M. E. \& Talbot, N. C. (1996). Pole-tilt sensor for surveyor range pole. Trimble Navigation Limited. https://www.google.com/patents/US5512905 (26.2.2017)

[36] USA Track \& Field - New England. Tool Tips for circular vials. (2007). http://www.usatfne.org/officials/electronic/ tool-tips-for-circular-vials.pdf (27.2.2017).

[37] Tuno, N., Omićević, Dž. \& Kogoj, D. (2012). Ispitivanje GPS RTK prijemnika GeotronicsGeotracer 2200. Geodetski glasnik, 45(40), 28-36.

\section{Contact information:}

Nedim TUNO, Assistant Professor PhD

Jusuf TOPOLJAK, Assistant Professor PhD

Naida ADEMOVIĆ, Associate Professor PhD

Admir MULAHUSIĆ, Associate Professor PhD

University of Sarajevo,

Faculty of Civil Engineering,

Patriotskelige 30, 71000 Sarajevo, Bosnia and Herzegovina

E-mail: nedim_tuno@gf.unsa.ba

E-mail: jusuf.topoljak@gf.unsa.ba

E-mail: naida_ademovic@gf.unsa.ba

E-mail: admir_mulahusic@gf.unsa.ba 